\title{
NOVOS LETRAMENTOS, ENSINO DE LÍNGUA ESTRANGEIRA E O PAPEL DA ESCOLA PÚBLICA NO SÉCULO XXI
}

\author{
New Literacies, Foreign Language Teaching and the Role of Public Schools in the 21st Century
}

Andrea Machado de Almeida MATTOS (UFMG)

RESUMO: O mundo de hoje se transforma contínua e rapidamente, e se torna cada vez mais "tecnologizado" ou "digitalizado" (LANKSHEAR; KNOBEL, 2003, p. 155). O contato entre culturas de diferentes partes do mundo torna-se cada vez mais possível e frequente (LEMKE, 1998). A presença de culturas diferentes em nosso próprio país e em nossa própria comunidade também fica cada vez mais evidente. Como acompanhar as mudanças da nossa sociedade frente às novas tecnologias? Qual o papel da educação na formação de indivíduos nesse novo mundo? O que significa ser cidadão no mundo de hoje? Qual o papel da escola pública na formação da cidadania? Como o ensino de língua estrangeira (LE) pode interferir nesse processo? Essas e outras questões serão aqui discutidas tendo como base as noções de diversidade cultural, globalização/localização, e as teorias de Letramento Crítico.

PALAVRAS-CHAVE: Novos letramentos; ensino de língua estrangeira; escola pública; cidadania.

ABSTRACT: Nowadays the world is rapidly and continuously changing, and is becoming increasingly "technologized" or "digitalized" (Lankshear; Knobel, 2003, p. 155). The contact between cultures of different parts of the world is becoming increasingly possible and frequent (Lemke, 1998). The presence of different cultures in our own country and in our own community is also increasingly evident. How can we track changes in our society in the face of new technologies? What is the role of schools in the education of individuals in this new world? What does it mean to be a citizen in today's world? What is the role of public schools in education for citizenship? How can teaching a foreign language (FL) interfere in this process? These and other issues will be discussed here based on the notions of cultural diversity, globalization / localization, and theories of critical literacy.

KEY WORDS: New literacies; foreign language teaching; public school; citizenship.

O mundo de hoje se transforma contínua e rapidamente, e se torna cada vez mais "tecnologizado" ou "digitalizado" (LANKSHEAR; KNOBEL, 2003, p. 155). Além disso, vivemos atualmente um intenso processo de globalização. $\mathrm{O}$ contato entre culturas de diferentes partes do mundo torna-se cada vez mais possível e frequente (LEMKE, 1998). A presença de culturas diferentes em nosso próprio país e em nossa própria comunidade também fica cada vez mais evidente. A educação, como não poderia deixar de ser, também tem sido fortemente influenciada pela globalização e pela presença da tecnologia. As novas tecnologias trouxeram a necessidade de se adquirir novas habilidades, o que Lankshear e Knobel (2003) chamaram de "novos letramentos". 
Nesse mundo em constante mutação, as instituições precisam aprender a se adaptar rapidamente às novas exigências de uma sociedade altamente letrada e tecnologizada. Mas o que é tecnologia? Como acompanhar as mudanças da nossa sociedade frente às novas tecnologias? Qual o papel da educação na formação de indivíduos nesse novo mundo? O que significa ser cidadão no mundo de hoje? Qual o papel da escola pública na formação da cidadania? Como o ensino de língua estrangeira (LE) pode interferir nesse processo? Essas e outras questões serão aqui discutidas tendo como base as noções de diversidade cultural, globalização/localização, e as teorias de Letramento Crítico.

É inquestionável que o mundo mudou (MENEZES DE SOUZA; MONTE MÓR, 2007). Se olharmos para trás, em pouco mais de 50 anos, o mundo se transformou à velocidade dos bits e continua se transformando a cada segundo. Essa transformação atinge todos os setores da nossa sociedade: a escola mudou, os meios de transporte mudaram, as relações no trabalho mudaram, para citar apenas alguns exemplos óbvios. A tecnologia tornou-se quase que onipresente em nossas vidas (LANKSHEAR; KNOBEL, 2003). Podemos dizer que aqui se aplica o que se convencionou chamar de "princípio da irreversibilidade", ou seja, independentemente de se ter ou não computador, a sociedade como um todo se utiliza da tecnologia e se transforma num ritmo digital, afetando todos os indivíduos a ela pertencentes. Nesse mundo em constante mutação, as instituições precisam aprender a se adaptar rapidamente às novas exigências de uma sociedade altamente tecnológica. Um pequeno exemplo ajudará a esclarecer como as instituições se reorganizam para se adaptar a essas novas exigências: a função primária dos correios, por exemplo, sempre foi entregar correspondências a seus destinatários. Com o advento do computador pessoal e o crescente uso do 'e-mail', a instituição teve que se adaptar para não perecer. Hoje a função principal dos correios deixou de ser a distribuição de correspondências pessoais e passou a ser a entrega de encomendas, muitas delas feitas através de sites de compra na Internet (COSCARELLI, 2008; PINSKY, 2005), ou seja, através da digitalização da informação e do uso da tecnologia.

Mas o que é tecnologia? Segundo o Novo Dicionário AURÉLIO da Língua Portuguesa, tecnologia é um "conjunto de conhecimentos, especialmente princípios científicos, que se aplicam a um determinado ramo de atividade." Para Menezes de Souza e Monte Mór (2006), no entanto, tecnologia é a aplicação de instrumentos específicos, inventados pela espécie humana, com o objetivo de estender nossas capacidades naturais. Nesse sentido, é possível pensar em tecnologias pré-científicas, ou tão antigas quanto o domínio do fogo, a invenção da roda e o advento da escrita. Essas tecnologias transformaram o mundo de forma irreversível.

A sociedade ocidental atual faz uso constante de práticas de leitura e escrita e, por isso, se caracteriza como uma sociedade "letrada" (SOARES, 2006). Novamente aqui, tem aplicação o 
chamado "princípio da irreversibilidade", desta vez mostrando que, embora em nossa sociedade alguns indivíduos não dominem a escrita (como crianças em idade pré-escolar e analfabetos, por exemplo), são eles também afetados pelo constante uso social da leitura e da escrita nos dias de hoje. Derrida (1967), ao discutir e criticar a centralidade e a universalidade da escritura na sociedade ocidental, já chamava atenção para o caráter universal que adquiriu a escrita, da forma como a conhecemos hoje. O filósofo assevera que, ao inventar "um sistema de signos gráficos que, no seu princípio, não se prende mais a nenhuma língua particular" (p. 366), já que em princípio é capaz de representar toda e qualquer língua, o homem acabou criando uma forma de escrita que adquiriu universalidade, tornando mais fácil a comunicação entre povos de línguas diferentes mas, ao mesmo tempo, criando a ilusão da clareza e da garantia da comunicação.

Juntamente com as mudanças e transformações físicas, sociais e culturais do mundo moderno, ocorreram também transformações conceituais. Lankshear e Knobel (2003, p. 155) afirmam:

Acreditamos que não foram apenas nossos letramentos $^{1}$ que foram fortemente impactados pela revolução da tecnologia da informação. Mais profundamente, toda a base epistemológica em que está fundamentada a abordagem da escola ao conhecimento e à aprendizagem está sendo seriamente desafiada e [...] tornada obsoleta pela intensa digitalização da vida diária.

O conceito de conhecimento já não corresponde mais ao conceito tradicional. Segundo Morin (2000), tradicionalmente o conhecimento é tratado de forma compartimentada, ou seja, por separação e redução, com o objetivo de facilitar a aprendizagem. Assim, o conhecimento pode ser separado em várias partes, como por exemplo no ensino de História, quando se separam os vários períodos da história da humanidade: Pré-História, Idade Antiga, Idade Medieval, Idade Moderna e Idade Contemporânea. Da mesma forma, o conhecimento pode ser reduzido ou simplificado, ensinando-se primeiro as partes mais simples para, aos poucos, acrescentar as partes mais complexas. Isso acontece, por exemplo, no ensino de inglês como língua estrangeira (LE), quando se ensinam primeiro os verbos regulares, considerados mais simples e fáceis, e depois os verbos irregulares, considerados mais complexos, ou quando se ensina o sistema modo-temporal dos verbos em inglês, começando-se pelo tempo verbal tradicionalmente considerado mais simples - o 'Present Simple' até chegar aos tempos mais complexos, como o 'Present Perfect' e o 'Past Perfect'. Contrapondo-se a essa prática tradicional, Menezes de Souza e Monte Mór (2006) sugerem uma "concepção epistemológica contemporânea" que defende a idéia de que "o conhecimento não deve ser apreendido de maneira fragmentada ou compartimentada" (p. 113). Pelo contrário, esses autores concordam com Morin (2000, p. 88) quando ele ressalta que:

\footnotetext{
${ }^{1}$ Itálico no original.
} 
há [...] necessidade de um pensamento que compreenda que o conhecimento das partes depende do conhecimento do todo e que o conhecimento do todo depende do conhecimento das partes; que reconheça e examine os fenômenos multidimensionais, em vez de isolar, de maneira mutiladora, cada uma de suas dimensões [...].

Assim como aconteceu com a concepção de conhecimento, a concepção de leitura também mudou. Até bem pouco tempo, leitura significava ler um texto escrito em papel, em uma direção prédeterminada, ou seja, de cima para baixo e da esquerda para a direita. Hoje em dia, principalmente após a intensificação do uso da Internet, essa concepção de leitura precisa ser revisada. No ambiente digital, a comunicação passa a ser multimodal, ou seja, a informação é fornecida não apenas em forma de texto escrito, mas também através de imagens e sons. Para Silver (1997), elementos multimodais podem incluir (mas não se restringem a) textos, fotografias, imagens e gráficos, clips de video e som, e até elementos de animação. Esses elementos, segundo o autor, podem estar dispostos "lado a lado numa única página, podem estar sobrepostos ou escondidos, e podem ser revelados através de um click num botão estratégico" (id. ibid., [sem paginação]). Isso significa que a escrita no ambiente digital perde a tradicional linearidade normalmente associada a textos escritos. A própria organização do texto escrito em páginas na Internet difere da organização de textos tradicionais. É possível, por exemplo, encontrarmos vários textos pequenos, relacionados ou não, dispostos em pontos diferentes da mesma página, o que permite que o leitor leia os vários textos na ordem que ele desejar. A própria presença da multimodalidade, isto é, de textos, imagens e sons diversos nas páginas da Internet, transforma o conteúdo a ser compreendido pelo leitor, pois "produz mensagens ou significados que não estão presentes apenas no texto escrito" (MENEZES DE SOUZA; MONTE MÓR, 2006, p. 105). Como ressaltam esses autores, "a inter-relação visual de cores ou de imagens com o texto escrito [...] [sugere] ao leitor que não há a necessidade de ler a página em sua totalidade, mas sim de optar por caminhos ou trajetos diferentes de "leitura'" (id. ibid.). Desta maneira, segundo Menezes de Souza e Monte Mór,

o conceito de leitura passa a ser primordialmente o exercício de uma opção de trajetória pela página e a subsequente aquisição seletiva de informações parciais presentes em diversos locais na mesma página [...] tornando complexa e multifacetada a experiência de 'ler' (id. ibid.).

A multimodalidade acaba por influenciar também a produção e a leitura de textos que anteriormente teriam sido produzidos e lidos de forma tradicional. Kress (2008) mostrou que jornais e revistas, por exemplo, hoje em dia trazem a presença de diferentes imagens, fotos, desenhos, e tipos e tamanhos de letras, o que os assemelha a textos encontrados no ambiente digital. A mídia externa, como por exemplo os chamados "out-doors", também acompanha essa nova revolução da escrita. A multimodalidade aparece até na televisão: esse ambiente primordialmente dominado pelo texto oral e pela imagem hoje faz uso de textos escritos, como legendas e flashes, que permitem que o 


\section{DOSSIÊ ESPECIAL \\ JORDÃO (org.) Letramentos e Multiletramentos no Ensino de Línguas e Literaturas.}

Revista X, vol.1, 2011

telespectador faça uso de sua capacidade multimodal de leitura. Kress e van Leeuwen (1996) lembram que é necessário considerar a questão da representação, ${ }^{2}$ ressaltando que a linguagem, no caso a linguagem visual, não é a realidade, mas apenas uma representação dela. Segundo eles, "o mundo representado visualmente na mídia de massa é um mundo diferente - e produz diferentes cidadãos/sujeitos - do mundo representado pela linguagem [escrita]” (p. 31).

A presença do ambiente digital em nossas vidas provoca, também, uma mudança na concepção de texto e desafia a questão da autoria. Um texto escrito é um texto considerado finalizado por seu autor, que possui um começo, um meio e um fim determinados, e que não pode ser alterado sob pena de se transformar em outro texto. O leitor desse texto pode identificar o seu autor (ou autores) que, claramente, é diferente de si mesmo. Ao ler o texto, o leitor também poderá certamente determinar o assunto principal e provavelmente os objetivos do autor. A leitura em ambiente digital, como foi dito, passa a ser não-linear ou multi-linear (Silver, 1997), pois o leitor tem a opção de escolher o percurso que deseja seguir. Esse percurso pode ser feito dentro de uma mesma página disponível na Internet ou pode constituir várias páginas diferentes, relacionadas ou não, que podem estar conectadas por "links" de hipertexto ${ }^{3}$ que "facilitam e promovem a leitura não-linear" (Coura Sobrinho, 2001). Ao final da leitura, depois de passar por várias páginas distintas, o leitor terá construído um texto inteiramente seu, que será diferente de todos os textos isolados contidos nas páginas que ele selecionou para ler. Assim, o leitor torna-se também co-autor do texto final, pois foi ele que o "construiu".

Essas e outras mudanças ocorridas recentemente em nossa sociedade desafiam a forma tradicional de se fazer a educação na escola regular. Para Kress e van Leeuwen (1996, p. 30), essas mudanças acabam por influenciar a formação das subjetividades e identidades dos leitores. As novas tecnologias trouxeram a necessidade de se adquirir novas habilidades, o que Lankshear e Knobel (2003) chamaram de "novos letramentos". Esses autores reafirmam que as mudanças ocorridas recentemente em nosso mundo devido à nossa crescente capacidade de digitalizar certos aspectos de nossas vidas, que por consequência alteram nossa experiência no mundo, desafiam as pressuposições tradicionais em que a escola atual tem-se embasado. A esse processo, os autores denominam “epistemologias digitais" (ibid, p. 156). A escola precisa se adaptar a essa nova necessidade social para que possa atingir seus objetivos educacionais, entre eles a formação de cidadãos plenos em sua capacidade de atuação em todos os níveis sociais. As teorias sobre novos letramentos e letramento

\footnotetext{
${ }^{2}$ Para Bourdieu (1996), é através da linguagem que representamos o mundo e a nós mesmos, ou seja, construímos nossas identidades. É, portanto, pela linguagem e na linguagem que construímos os significados, ou seja, as representações, do mundo a nossa volta. ${ }^{3}$ De acordo com Silver (1997), o termo hipertexto foi cunhado por Theodor H. Nelson, pioneiro na área computacional. Nelson (1981) refere-se ao texto eletrônico enquanto "escrita não-sequencial" que ele define como um texto que oferece ao leitor diversos caminhos de leitura.
} 
crítico parecem oferecer um caminho que pode permitir um avanço no papel da escola em relação à formação de indivíduos nesse novo mundo e à formação para a cidadania.

\section{NOVOS LETRAMENTOS}

Para compreender o conceito de letramento, façamos primeiro um paralelo com o conceito de alfabetização. Soares (2006, p. 16) diz que "alfabetizar é ensinar [alguém] a ler (e também a escrever) ${ }^{4}$." A autora nos lembra que o termo 'letramento' vem do original em inglês 'literacy' que significa "o estado ou condição que assume aquele que aprende a ler e escrever" (SOARES, 2006, p. 17). A autora define, então, letramento como "O resultado da ação de ensinar ou de aprender a ler e escrever: o estado ou a condição que adquire um grupo social ou um indivíduo como consequência de ter-se apropriado da escrita" (ibid, p.18).

Soares (2006) diz, ainda, que o letramento possui uma dimensão individual e outra social. $\mathrm{Na}$ dimensão individual, o letramento resume-se a uma simples posse das habilidades de ler e escrever. Note-se, porém, que o indivíduo que possui essas habilidades não é apenas alfabetizado (no sentido de que reconhece o alfabeto e consegue assinar seu próprio nome), mas também letrado (no sentido de que é capaz de ler textos, ainda que num nível básico, e escrever mensagens simples, pelo menos). Já em sua dimensão social, o letramento torna-se um fenômeno cultural e passa a ser caracterizado por "um conjunto de atividades sociais que envolvem a língua escrita, e de exigências sociais de uso da língua escrita” (ibid, p. 66). É nessa concepção, ou seja, em sua dimensão social, que, segundo a autora,

a escrita traz consequências sociais, culturais, políticas, econômicas, cognitivas, linguísticas, quer para o grupo social em que seja introduzida, quer para o indivíduo que aprende a usá-la. (ibid, p. 17).

De acordo com Street (1984, p. 1), letramento é "um termo-síntese para resumir as práticas sociais e concepções de leitura e escrita." O autor identificou dois modelos que podem ajudar a compreender o conceito de letramento: o modelo autônomo e o modelo ideológico. O modelo autônomo postula que letramento é um conjunto de habilidades técnicas neutras e independentes do contexto social em que são usadas. São essas habilidades que permitem que o indivíduo funcione adequadamente em um contexto social. Num contexto educacional, as habilidades percebidas como “corretas" são definidas e a aprendizagem torna-se focada na reprodução mecânica dessas habilidades. Acredita-se que essas habilidades podem ser facilmente transferidas para a vida real. Assim, no ensino de línguas estrangeiras, por exemplo, especialmente no ensino de inglês, usou-se

\footnotetext{
${ }^{4}$ Itálico no original.
} 
durante muito tempo a repetição na forma de drills como método principal de aprendizagem. Descobriu-se, porém, que as frases repetidas e praticadas em sala de aula raramente podiam ser transferidas e usadas pelos aprendizes em contextos reais. Essa forma de ensino/aprendizagem, contudo, ainda não foi totalmente abandonada por professores e educadores e permanece viva em muitos contextos de ensino de língua estrangeira.

O modelo ideológico, também chamado de 'modelo de práticas sociais', proposto como alternativa para o modelo autônomo, reconhece a natureza sócio-cultural do letramento (STREET, 1984). Trabalhando dentro do modelo ideológico, Hamilton (2000, p. 1) ressalta que letramento é um conceito relacional definido pelas práticas sociais e comunicativas em que os indivíduos se engajam nos vários domínios de suas vidas e do mundo, ou seja, definir as chamadas 'habilidades corretas' depende das relações sociais e individuais de cada pessoa envolvida no processo. Dessa maneira, qualquer definição de letramento depende necessariamente das práticas sociais e comunicativas dos indivíduos e grupos sociais envolvidos. Nesse modelo, "o letramento é visto como um instrumento da ideologia, utilizado com o objetivo de manter as práticas e relações sociais correntes, acomodando as pessoas às condições vigentes" (SOARES, 2006, p. 76). Parte-se do pressuposto de que a prática do letramento nos contextos educacionais está "intimamente relacionada com processos sociais mais amplos, determinadas por eles, e resultam de uma forma particular de definir, de transmitir e de reforçar valores, crenças, tradições e formas de distribuição de poder" (id. ibid.).

Abraçar o modelo ideológico de letramento significa buscar mudanças nesse quadro. Para isso, o aprendiz deve passar a ser o detentor do poder para determinar o conteúdo e o currículo de sua aprendizagem, e não a instituição educacional. Essa abordagem reflete questões que são derivadas dos próprios interesses e conhecimento de mundo dos aprendizes e só muito recentemente começa a ganhar força no cenário mundial. No Brasil, os primeiros passos nessa direção também começam a ganhar adeptos. Com o lançamento das novas Orientações Curriculares para o Ensino Médio Conhecimentos de Línguas Estrangeiras (MENEZES DE SOUZA; MONTE MÓR, 2006), que colocam em evidência as recentes mudanças ocorridas em nossa sociedade e a urgente necessidade de reformulação das práticas educacionais, a discussão sobre os desafios epistemológicos a serem enfrentados pela escola, principalmente no âmbito do ensino público, começa a ser levada a efeito também no cenário nacional. As Orientações Curriculares para o Ensino Médio - Línguas Estrangeiras (OCEM/LE) ressaltam "a relevância da noção de cidadania" (p. 87) no contexto da escola pública.

\section{LETRAMENTO, GLOBALIZAÇÃO E CIDADANIA}


A globalização vem trazendo mudanças exponenciais para a sociedade como um todo. Segundo Suárez-Orozco e Qin-Hilliard (2004, p. 1), o termo "define a nossa era" e significa a aceleração dos movimentos de pessoas, mercadorias e ideias entre diferentes países e regiões do mundo (COATSWORTH, 2004). Suárez-Orozco e Qin-Hilliard (2004, p. 1) afirmam, ainda, que esse processo "parece estar profundamente relacionado a praticamente todas as grandes questões do novo milênio".

Waks (2006) diz que o termo já foi definido segundo conceitos econômicos, tecnológicos, sociais e culturais. Em termos econômicos, o processo de globalização está relacionado ao aumento das relações de mercado ao redor do mundo, como o crescimento das transações entre diferentes nações e o consequente aumento do movimento de pessoas entre fronteiras nacionais. Em termos tecnológicos, a globalização está relacionada ao "rápido crescimento de redes de informação e [a]o fluxo instantâneo de informação e comércio através de fronteiras nacionais, por exemplo, na Internet” (ibid., p. 413). Como consequência desses movimentos, o mundo passa a ser visto em termos de uma "economia global unificada" ou um "mundo sem fronteiras" (id. ibid.). Em termos sociais e culturais, Waks (2006, p. 413) relaciona a globalização ao aumento das

\footnotetext{
relações extra-econômicas sociais e culturais para além das fronteiras nacionais, criando tanto um grau de homogeinização cultural, com uma crescente consciência de humanidade como de certa forma constituindo uma única sociedade global, quanto novas formas de heterogeneidade cultural, hibridismo ou 'glocalização'.
}

A educação, como já dito, também tem sido fortemente influenciada pela globalização que, ao alterar as relações econômicas, políticas, sociais e culturais em nível mundial, também introduz novos elementos na escola em geral e na sala de aula, especificamente.

Segundo as OCEM/LE, essa nova ordem social globalizada evidencia "necessidades da sociedade atual [que] apontam para um trabalho educacional em que as disciplinas do currículo escolar se tornam meios [para] a formação de indivíduos" (MENEZES DE SOUZA; MONTE MÓR, 2006, p. 90). Para os autores das OCEM/LE, o papel da educação no âmbito da escola regular passa a incluir, assim, além da produção de conhecimento tradicional, a formação de indivíduos, de cidadãos.

Para se chegar a esse objetivo, é necessário compreender o conceito de cidadania, "um valor social a ser desenvolvido nas várias disciplinas escolares", nas palavras de Menezes de Souza e Monte Mór (ibid, p. 91). Na visão de Ruscheinsky (1999, p. 30), cidadão é aquele que "têm direito de participar de decisões que afetam diretamente sua vida" e, ao mesmo tempo, tem acesso à "multiplicidade de espaços nos quais pode exercer tal direito" (id. ibid.). Portanto, para ser cidadão, 
primeiramente é preciso estar em pleno gozo de seus direitos civis, mas também é preciso, acima de tudo, ter acesso a situações e contextos em que esse direito pode ser exercido plenamente. Para isso, na opinião de Menezes de Souza e Monte Mór (2006, p. 91),

\footnotetext{
ser cidadão envolve a compreensão sobre que posição/lugar uma pessoa (o aluno, o cidadão) ocupa na sociedade, ou seja, de que lugar ele fala na sociedade? Por que essa é a sua posição? Como veio parar ali? Ele quer estar nela? Quer mudá-la? Quer sair dela? Essa posição o inclui ou o exclui de quê?
}

A partir dessas definições, vemos que o conceito de cidadania envolve a tomada de decisões, ou práticas sociais, por parte de sujeitos ativos localizados socio-historicamente. A noção de globalização, ou seja, o atual processo de movimentação entre os povos que caracteriza a sociedade atual, se contrapõe claramente à noção de localização. Chiarini (2001, p. 73) descreve a sociedade atual como um "cenário híbrido, plural, globalizado e, ao mesmo tempo, marcadamente atravessado por reivindicações locais." É nesse "cenário híbrido" que se dá o atual debate sobre a globalização e as questões de poder envolvidas no embate entre uma postura globalizante da educação, que acaba por reproduzir as relações de poder já existentes e de interesse dos grupos dominantes, e uma abordagem mais localizante, que não pretende se opor à globalização, mas que objetiva ao empoderamento e à libertação dos educandos (cidadãos), subvertendo a ordem dominante e buscando alternativas locais para a mudança.

Para tanto, é necessário conhecer e reconhecer nosso lugar no mundo: quem somos nós? Como contribuímos para a nossa comunidade? Como a nossa cultura nos influencia? Refletir sobre nossos valores locais, ou seja, aquilo que é "regional, interior, de uma comunidade ou de grupos com características próprias" (MENEZES DE SOUZA; MONTE MÓR, 2006:96), e contrapô-los a valores globais, ou seja, aquilo que é "universal, exterior, de um grupo de países desenvolvidos, que, por sua força político-econômica, se apresentam como modelos sociais" (id. ibid.), nos ajuda a perceber a forte hierarquização existente entre esses dois tipos de valores e a fazer opções mais informadas quanto a que posição assumir frente a diferentes situações.

Um tipo de educação que tenha por objetivo a formação da cidadania do educando não pode deixar de fora a questão da inclusão social, frente a uma inquestionável realidade de exclusão no cenário brasileiro. Menezes de Souza e Monte Mór (ibid.) ressaltam que a questão da inclusão social passa por políticas públicas preocupadas com a exclusão, que é uma "situação indesejável”. Porém, para eles, a preocupação com a inclusão social, que pode significar "integração social traduzida por emprego, sucesso profissional, melhoria da vida material e bem estar" (p. 96), não pode ser dissociada de "uma consciência crítica da diversidade sociocultural e linguística" (ibid.) da sociedade atual. O letramento crítico e o uso das novas tecnologias e novos letramentos na escola podem 
contribuir para a conscientização de educandos e de professores pela reflexão crítica e pelo questionamento das práticas dominantes de leitura e escrita no ambiente escolar.

O letramento enquanto prática educacional, como foi dito, visa ao aprendizado da linguagem escrita (SOARES, 2006). Já o letramento crítico, segundo o site britânico Critical Literacy in Global Citizenship Education online $e^{5}$, é "uma prática educacional que focaliza a relação entre linguagem e visões de mundo, práticas sociais, poder, identidade, cidadania, relações interculturais e questões de globalização/localização." O objetivo seria "aprender a relacionar-se com o mundo e a pensar o mundo de formas diferentes" das tradicionais. Norton (2007, p. 6) concorda que a “concepção dominante de letramento (...) é que letramento se refere à habilidade, por parte dos indivíduos, de ler e escrever." A autora acrescenta que essa concepção não deixa de ser útil e importante, mas que a concepção de "letramento crítico" é mais ampla, envolvendo questões socioculturais e políticas. Para a autora, "educadores interessados em letramento crítico estão interessados no texto escrito, ou, mesmo, em qualquer outro tipo de representação do significado, como local de luta, negociação e mudança" (p. 6).

Cervetti, Pardales e Damico (2001) comparam a concepção de letramento crítico com as noções de leitura crítica que, segundo eles, por serem duas abordagens de letramento, vem sendo confundidas ultimamente, mas que, além de terem diferentes origens teóricas, possuem “visões muito diferentes, talvez incompatíveis, sobre conhecimento, realidade, autoria, e discurso e sobre os objetivos da educação" (p. 1). Os autores discutem as concepções que embasam as noções de leitura crítica e contrastam essas concepções com as propostas do letramento crítico. Para os autores, leitura crítica se define como um conjunto de habilidades que permitem ao leitor "investigar fontes, reconhecer o propósito de um autor, distinguir fato e opinião, fazer inferências, formar julgamentos, e detectar estratégias de propaganda" (p. 2). Essas habilidades, que estendem as capacidades do indivíduo para além de um letramento dito funcional (SOARES, 2006) e permitem "níveis mais altos de análise e compreensão" (CERVETTI; PARDALES; DAMICO, 2001, p. 2), precisam ser ensinadas explicitamente, já que não se desenvolvem naturalmente nos leitores.

Bond e Wagner (1966, p. 283) dizem que "leitura crítica é o processo de avaliação da autenticidade e da validade do material e de formulação de opinião sobre ele." Contrariamente, no letramento crítico, o objetivo dos leitores não é a interpretação, mas a construção de significados a partir do texto. Além disso, "o significado textual é compreendido no contexto das relações sociais, históricas e de poder, não apenas como o produto ou intenção de um autor" (CERVETTI; PARDALES; DAMICO, 2001, p. 6). A leitura, segundo esses mesmos autores, passa a ser vista

\footnotetext{
${ }^{5}$ www.criticalliteracy.org.uk
} 
como um processo de conhecimento do mundo, e não apenas da palavra (ou do texto escrito), e "um meio para a transformação social" (id. ibid.).

McLaughlin e DeVoogd (2004, p. 14) afirmam que o letramento crítico considera "os leitores como participantes ativos no processo de leitura", permitindo que os leitores deixem de "aceitar passivamente a mensagem do texto para questionar, examinar e desafiar as relações de poder que existem entre leitores e autores." Esses autores concordam com Cervetti, Pardales e Damico, quando dizem que o letramento crítico "promove a reflexão, a transformação e a ação" (id. ibid.), segundo a visão freiriana de transformação social. Para Morgan (1997, p. 2), a prática do letramento crítico leva os leitores a questionar

\footnotetext{
quem constrói os textos [ou perspectivas/discursos/ideologias]; que representações são dominantes numa cultura determinada num determinado tempo; como os leitores passam a ser cúmplices das ideologias persuasivas dos textos; que interesses são privilegiados por tais representações e tais leituras; e, quando tais textos e leituras são injustos em seus efeitos, de que outra maneira eles poderiam ser construídos.
}

Dessa forma, o letramento crítico coloca em evidência as relações de poder que imperam em nossa sociedade e se preocupa especialmente com as diferenças entre raça, classe social, gênero, orientação sexual, etc., examinando-as "não como ocorrências isoladas, mas como parte de desigualdades e injustiças sistêmicas" (CERVETTI; PARDALES; DAMICO, 2001, p. 6). Algumas das principais preocupações do letramento crítico estão resumidas na tabela 1 abaixo:

\begin{tabular}{|l|l|}
\hline \multicolumn{1}{|c|}{ Conceito } & \multicolumn{1}{c|}{ Visão de acordo com o Letramento Crítico } \\
\hline $\begin{array}{l}\text { Conhecimento } \\
\text { (epistemologia) }\end{array}$ & $\begin{array}{l}\text { O conhecimento não é natural nem neutro; conhecimento é } \\
\text { sempre baseado nas regras discursivas de uma determinada } \\
\text { comunidade e, por isso, é ideológico. }\end{array}$ \\
\hline $\begin{array}{l}\text { Realidade } \\
\text { (ontologia) }\end{array}$ & $\begin{array}{l}\text { A realidade não pode ser conhecida definitivamente e não } \\
\text { pode ser capturada na linguagem; decisões sobre o que é a } \\
\text { verdade não podem ser baseadas numa correspondência direta } \\
\text { com a realidade, mas devem ser tomadas no âmbito local. }\end{array}$ \\
\hline Autoria & $\begin{array}{l}\text { O significado textual é sempre múltiplo, contestável, } \\
\text { culturalmente e historicamente situado, e construído de acordo } \\
\text { com as diferentes relações de poder. }\end{array}$ \\
\hline Educação & Desenvolvimento da consciência crítica. \\
\hline
\end{tabular}

Tabela 1: Principais conceitos do Letramento Crítico (adaptado de CERVETTI, PARDALES e DAMICO, 2001, p. 10).

Lima (2006) traz a prática do letramento crítico para o campo do ensino de inglês como língua estrangeira e ressalta que o letramento crítico é inter-disciplinar e surgiu a partir de "teorias recentes sobre globalização, movimentos sociais e a relação entre língua, conhecimento e poder" (p. 2). Para a autora, "a principal diferença entre letramento crítico e outras práticas educacionais no 
ensino de língua é a maneira como a linguagem é concebida" (id. ibid.). A tabela 2 abaixo resume as noções de linguagem de acordo com a perspectiva tradicional, dominante no ensino de língua e de acordo com o letramento crítico:

\begin{tabular}{|l|l|}
\hline \multicolumn{1}{|c|}{ Noção Dominante de Linguagem } & \multicolumn{1}{|c|}{ Noção segundo o Letramento Crítico } \\
\hline $\begin{array}{l}\text { A linguagem traduz ou representa a } \\
\text { realidade }\end{array}$ & $\begin{array}{l}\text { Linguagem e realidade se constroem } \\
\text { mutuamente }\end{array}$ \\
\hline A linguagem é um meio de comunicação & $\begin{array}{l}\text { A linguagem constrói a comunicação pela } \\
\text { negociação. Ela não comunica ideias e } \\
\text { valores, mas sim cria ideias e valores. }\end{array}$ \\
\hline A linguagem é transparente e neutra & $\begin{array}{l}\text { A linguagem nunca é neutra ou } \\
\text { transparente. Ela sempre é culturalmente } \\
\text { "tendenciosa". }\end{array}$ \\
\hline $\begin{array}{l}\text { A linguagem é fixa e definida por normas } \\
\text { sociais (ex: gramáticas e dicionários) }\end{array}$ & $\begin{array}{l}\text { A linguagem é sempre estruturada, mas } \\
\text { suas estruturas não são fixas ou estáveis. } \\
\text { Elas mudam dinamicamente de acordo } \\
\text { com o contexto. }\end{array}$ \\
\hline
\end{tabular}

Tabela 2: Noções de linguagem (LIMA, 2006). ${ }^{6}$

Como é possível perceber, então, a partir dessa noção de linguagem, o letramento crítico coloca em foco as relações de poder expressas através da língua. Segundo o site britânico Critical Literacy in Global Citizenship Education online, já citado, "o letramento crítico trata a complexidade e promove o pensamento independente, relações éticas e processos participativos de tomada de decisão."

\section{CONCLUSÃO: O PAPEL DA EDUCAÇÃO E O ENSINO DE LÍNGUA ESTRANGEIRA NA ESCOLA PÚBLICA}

Segundo Waks (2006, p. 412), a escola tornou-se uma das "burocracias administrativas estatais mais importantes nos estados liberais e liberais democráticos da era industrial." Isso porque, através da escola, o estado passou a controlar e manipular o comportamento cívico e econômico dos indivíduos, "usando seu aparato educacional para legitimar seu uso da coerção" (id. ibid.). Da mesma maneira, como afirma Lankshear (1987, p. 131), "a transmissão e a prática do letramento na escola contribuem para a manutenção de padrões desiguais de distribuição de poder e de vantagens dentro da estrutura social."

\footnotetext{
${ }^{6}$ Tradução minha.
} 
O letramento crítico e o uso das novas tecnologias/novos letramentos na escola podem contribuir para alterar essa situação, através da conscientização dos educandos pela reflexão crítica e pelo questionamento das práticas dominantes de leitura e escrita no ambiente escolar. Lemke (1998), por exemplo, afirma que se considerarmos que a educação é uma forma de iniciação às práticas de uma comunidade, principalmente às suas práticas gerais e especializadas de letramento,

novas tecnologias de informação, novas práticas de comunicação, e novas redes sociais tornam possíveis novos paradigmas para a educação e a aprendizagem, e desafiam as pressuposições em que se baseiam os velhos paradigmas (p. 7).

O ensino de língua estrangeira, principalmente o inglês, na escola regular se justifica em vista das exigências tecnológicas e mercadológicas de nossa sociedade. A necessidade de prestigiar o ensino de língua estrangeira na grade curricular da escola pública é ainda mais premente, já que o aluno da escola pública normalmente não dispõe de outros meios de acesso a esse conhecimento.

Tendo em vista a sociedade globalizada atual, o ensino de LE passa a ter como objetivo permitir o acesso do aluno, principalmente o aluno da escola pública, a novas tecnologias, criando possibilidades de o cidadão (aluno) dialogar com outras culturas sem que haja necessidade de abrir mão de seus valores locais (MENEZES DE SOUZA; MONTE MÓR, 2006).

Shor (1999, p. 13) nos lembra que "a aprendizagem de uma língua é o processo pelo qual a criança passa a adquirir uma identidade social específica." Ao aprender uma língua estrangeira, então, a criança (ou adolescente) passa a desenvolver uma nova identidade social. Os professores de LE, assim, têm um papel primordial na formação dessa nova identidade social do cidadão, já que são eles, conforme Gee (1986), as pessoas que socializam os aprendizes nessa nova visão de mundo trazida pela língua estrangeira.

\section{REFERENCIAS}

BOND, G. L.; WAGNER, E. B. Teaching the child to read. (4 ${ }^{\text {th }}$ ed.) New York: Macmillan, 1966.

BOURDIEU, P. A linguagem autorizada: as condições sociais da eficácia do discurso ritual. In: . A economia das trocas lingüísticas: o que falar quer dizer. Tradução de Sergio Miceli.

São Paulo: EDUSP, 1996. p. 81-96.

CERVETTI, G.; PARDALES, M. J.; DAMICO, J. S. A tale of differences: comparing the traditions, perspectives and educational goals of critical reading and critical literacy. Reading Online, v. 4, n. 9, April 2001. Disponível em: $<$ http://www.readingonline.org/articles/art_index.asp?HREF=articles/cervetti/index.html>. Acesso em: 30 mar. 2007. 
CHIARINI, A. M. Língua e cultura na globalização: algumas implicações na sala de aula de língua estrangeira. In: CONGRESSO DA ASSOCIAÇÃO DE PROFESSORES DE LÍNGUA INGLESA DO ESTADO DE MINAS GERAIS \& ENCONTRO DE PROFESSORES DE LÍNGUAS ESTRANGEIRAS DO CEFET-MG, 3, 2001, Belo Horizonte. Anais...Iniciativas para o ensino de línguas estrangeiras. Belo Horizonte: APLIEMGE / CEFET-MG, 2001. p. 72-79.

COATSWORTH, J. H. Globalization, growth, and welfare in history. In: SUÁREZ-OROZCO, M. M. \& QIN-HILLIARD, D. B. (Eds.). Globalization: culture and education in the new millennium. Berkeley e Los Angeles: University of California Press/The Ross Institute, 2004. p. 38-55.

COSCARELLI, C. Letramento Digital. In: EDUCONLE, 2008, Belo Horizonte. Palestra de Abertura... Belo Horizonte, 2008. Apresentação oral.

COURA SOBRINHO, J. Computador: uma caixa de Pandora ou uma caixa preta? In: CONGRESSO DA ASSOCIAÇÃO DE PROFESSORES DE LÍNGUA INGLESA DO ESTADO DE MINAS GERAIS \& ENCONTRO DE PROFESSORES DE LÍNGUAS ESTRANGEIRAS DO CEFET-MG, 3, 2001, Belo Horizonte. Anais... Iniciativas para o ensino de línguas estrangeiras. Belo Horizonte: APLIEMGE / CEFET-MG, 2001. p. 122-128.

DERRIDA, J. Gramatologia. 2. ed. São Paulo: Perspectiva, 1967.

GEE, J. P. Orality and literacy: from the savage mind to ways with words. TESOL Quarterly, v. 20, n. 4, 1986, p. 719-746.

HAMILTON, M. Sustainable literacies and the ecology of lifelong learning. In: Supporting Lifelong Learning Global Colloquium, University of East London. Paper... London, July 2000. Disponível em: <http://www.open.ac.uk/lifelong-learning/papers/index.html>. Acesso em: 28 maio 2008.

KRESS, G. Multimodality and Learning: new perspectives on knowledge, representation and communication. In: VISITAS INTERNACIONAIS DO INSTITUTO DE ESTUDOS AVANÇADOS TRANSDISCIPLINARES/UFMG, 2008, Belo Horizonte. IEAT/UFMG, 2008. Apresentação oral.

KRESS, G.; van LEEUWEN, T. Reading images: the grammar of visual design. London/New York: Routledge, 1996.

LANKSHEAR, C. Literacy, schooling and revolution. New York: the Falmer Press, 1987.

LANKSHEAR, C.; KNOBEL, M. New literacies: changing knowledge and classroom learning. Buckingham: Open University Press, 2003.

LEMKE, J. L. Metamedia literacy: transforming meanings and media. In: REINKING, D. et al (Eds.) Literacy for the $21^{\text {st }}$ Century: technological transformation in a post-typographic world. Hillsdale, NJ: Erlbaum, $1998 . \quad$ p. 238-301. Disponível em: <http://academic.brooklyn.cuny.edu/education/jlemke/reinking.htm>. Acesso em: 9 fev. 2007.

LIMA, C. A brief introduction to critical literacy in English language education. Brasília: ELTECS/British Council Brazil/CSSGJ(University of Nottingham), 2006. Disponível em: <http://www.criticalliteracy.org.uk/elt $>$. Acesso em: 3 fev. 2008.

McLAUGHLIN, M.; DeVOOGD, G. L. Critical literacy: enhancing students' comprehension of text. New York: Scholastic, 2004.

MENEZES DE SOUZA, L. M. T.; MONTE MÓR, W. M. Orientações curriculares para o ensino médio: linguagens, códigos e suas tecnologias - conhecimentos de línguas estrangeiras. Brasília: 
Ministério da Educação / Secretaria de Educação Básica, 2006. Disponível em: $<$ http://portal.mec.gov.br/seb/arquivos/pdf/book_volume_01_internet.pdf>. Acesso em: 6 fev. 2008.

New challenges in language teaching (As novas Orientações Curriculares para o Ensino Médio: Língua Inglesa). In: I Congresso Internacional da ABRAPUI, 2007, Belo Horizonte, Minas Gerais. Caderno de Resumos...Novos desafios em língua e literatura. Belo Horizonte, 2007. p. 23.

MORGAN, W. Critical literacy in the classroom: the art of the possible. New York: Routledge, 1997.

MORIN, E. Acabeça bem-feita: repensar a reforma - reformar o pensamento. Rio de Janeiro: Bertrand Brasil, 2000.

NELSON, T. H. Literacy Machines. Swarthmore, PA: self-published, 1981. apud SILVER, D. Multimedia, multilinearity, and multivocality in the hypermedia classroom. Computers \& Texts, $\mathrm{n}$. 14, April 1997. Disponível em: <http://users.ox.ac.uk/ ctitext2/publish/comtxt/ct14/silver.html> Acesso em: 04 jun. 2008.

NORTON, B. Critical literacy and international development. Critical Literacy: Theories and Practices, v. 1, n. 1, 2007, p. 6-15. Disponível em: < http://www.criticalliteracy.org.uk/images/journal/v1issue1/norton.pdf>. Acesso em: 22 mai. 2008.

PINSKY, J. Cidadania e educação. 9. ed. São Paulo: Contexto, 2005.

RUSCHEINSKY, A. Cidadania e construção do conhecimento ante a expressão de interesses. In: LAMPERT, E. (Org.) Educação para a cidadania: gênero, etnia, políticas educacionais, competência docente/discente. Porto Alegre: Fundação Universidade do Rio Grande/Editora Sulina, 1999. p. 13-32.

SILVER, D. Multimedia, multilinearity, and multivocality in the hypermedia classroom. Computers \& Texts, n. 14, April 1997. Disponível em: <http://users.ox.ac.uk/ ctitext2/publish/comtxt/ct14/silver.html>. Acesso em: 04 jun. 2008.

SHOR, I. What is critical literacy? Journal for Pedagogy, Pluralism \& Practice, v. 1, n. 4, 1999. Disponível em: <http://www.lesley.edu/journals/jppp/4/shor.html>. Acesso em: 12 fev. 2008.

SOARES, M. Letramento: um tema em três gêneros. Belo Horizonte: Autêntica, 2006.

STREET, B. Literacy in theory and practice. Cambridge: Cambridge University Press, 1984.

SUÁREZ-OROZCO, M. M. \& QIN-HILLIARD, D. B. (Eds.). Globalization: culture and education in the new millennium. Berkeley e Los Angeles: University of California Press/The Ross Institute, 2004.

WAKS, L. J. Globalization, state transformation, and educational re-structuring: why postmodern diversity will prevail over standardization. Studies in Philosophy and Education, v. 25, n. 5, 2006, p. 403-424. 